\title{
Seasonal Variation in High Arctic Stratospheric Aerosols Observed by Lidar at Ny Ålesund, Svalbard between March 2014 and February 2018
}

\author{
Koichi Shiraishi ${ }^{1}$ and Takashi Shibata ${ }^{2}$ \\ ${ }^{1}$ Faculty of Science, Fukuoka University, Fukuoka, Japan \\ ${ }^{2}$ Nagoya University, Nagoya, Japan
}

\begin{abstract}
Stratospheric aerosols over the high Arctic at Ny Alesund, Svalbard $\left(79^{\circ} \mathrm{N}, 12^{\circ} \mathrm{E}\right)$ were observed continuously for four years from March 2014 by a lidar system using the second harmonic wavelength $(532 \mathrm{~nm})$ of the Nd:YAG laser. Our observations reveal the seasonal features of stratospheric aerosols and the arrival of the smoke at the high Arctic from Canadian forest-fire in August 2017. We estimated the seasonal variation for three years before the Canadian forest-fire when there was no apparent volcanic effect. In the estimation, we removed polar stratospheric clouds by the threshold temperature of their formation. The seasonal variation for the three years is that the vertical profiles of the backscattering ratio take a maximum value of about 1.05-1.06 at altitudes between 13 and $16 \mathrm{~km}$ from December to March, and about 1.02-1.04 at altitudes between 17 and $20 \mathrm{~km}$ from April to November. These results are compared with the results observed at the low Arctic, northern Norway. We also present the increases in the backscattering ratio and the volume depolarization ratio from September to December 2017 caused by the smoke from the Canadian forest-fire.
\end{abstract}

(Citation: Shiraishi, K., and T. Shibata, 2021: Seasonal variation in high arctic stratospheric aerosols observed by Lidar at $\mathrm{Ny}$ Ålesund, Svalbard between March 2014 and February 2018. SOLA, 17, 30-34, doi:10.2151/sola.2021-005.)

\section{Introduction}

Stratospheric aerosols play important roles in the radiative and chemical processes of the stratosphere. Many lidar-observational efforts at mid and low latitudes have therefore been devoted to characterize the seasonal and long-term variations of stratospheric aerosols in order to study these processes (e.g. Sakai et al. 2016; Khaykin et al. 2017). Over the Arctic, background stratospheric aerosols also work as a precursor in the formation of polar stratospheric clouds (PSC) which provide the surfaces for the heterogeneous reactions of the ozone depletion process (e.g. Lowe and MacKenzie 2008). Ground-based lidar systems operating in the high Arctic have been frequently applied to observe PSC (e.g. Shiraishi et al. 2003; Shiraishi 2010). Nevertheless, lidar observations of Arctic stratospheric aerosols throughout the year are quite limited since lidar observations of stratospheric aerosols are quite problematic in the summer midnight sun season. The only report to date of stratospheric observations throughout the year in the Arctic is by Langenback et al. (2019). They presented a seasonal variation of stratospheric aerosols over the Arctic for the first time by year-round lidar observations from 2014 to 2017 at a site in the low Arctic, northern Norway $\left(69^{\circ} \mathrm{N}, 16^{\circ} \mathrm{E}\right)$. However, there has been no report on the seasonal variation of stratospheric aerosols over the high Arctic.

We performed continuous lidar observations of aerosols and clouds over the high Arctic at Ny Ålesund, Svalbard $\left(79^{\circ} \mathrm{N}, 12^{\circ} \mathrm{E}\right)$ for four years from March 2014. The lidar system used for the observations was a Nd:YAG laser-based Mie scattering lidar

Corresponding author: Koichi Shiraishi, Department of Earth System Science, Faculty of Science, Fukuoka University, 8-19-1 Nanakuma, Jonanku, Fukuoka 814-0180, Japan. E-mail: siraisi@fukuoka-u.ac.jp. designed mainly for observations of the troposphere. Shibata et al. (2018) reported the seasonal variation of tropospheric aerosols from March 2014 to December 2017 using this system. The lidar system is also partially useful for observations of stratospheric aerosols. In this letter, we present the results of continuous observations of stratospheric aerosols for four years from March 2014 to February 2018. Perturbations by PSC were observed for short periods during the winters. The perturbation caused by smoke from Canadian forest fires was observed for about half a year from September 2017. Because there were no apparent perturbations at other periods in these four years, we attempted to discover the seasonal variation of unperturbed stratospheric aerosols during this period by removing the effect of PSC by excluding the data points where the temperature was lower than the threshold temperature of PSC-formation. We present resulting seasonal variation of the lidar observed stratospheric aerosols over the high Arctic for these four years.

\section{Data and method}

The observation site of the stratospheric aerosols was at the high Arctic, Ny Ålesund, Svalbard $\left(79^{\circ} \mathrm{N}, 12^{\circ} \mathrm{E}\right)$. The details of the lidar system and the observations have been described by Shibata et al. (2018). The background noise not only in darkness without the sun but also in the brightness of sun light was small enough for stratospheric lidar observations. An interference filter with narrow bandwidth $(0.3 \mathrm{~nm}, \mathrm{FWHM})$ was used to eliminate noise due to scattered solar radiation. The data used for stratospheric analysis were taken at $532 \mathrm{~nm}$ by photon counting mode. We set the original vertical resolution of the profiles to $90 \mathrm{~m}$ and applied a running mean setting the final resolution to $810 \mathrm{~m}$. The number of days when stratospheric aerosols were observed was 391 in the four years from March 2014 to February 2018. We used 4 hours of integrated observations to obtain one stratospheric vertical profile. The total number of profiles was 920 .

The observed data were normalized with the Rayleigh backscattering coefficient of atmospheric molecules $\left(\beta_{\mathrm{R}}\right)$ at altitudes higher than approximately $30 \mathrm{~km}$. $\beta_{\mathrm{R}}$ is proportional to the density of the atmospheric molecules, calculated from the ERA-Interim reanalysis data obtained by the European Centre for MediumRange Weather Forecasts. The effect of absorption by ozone was also estimated in the calculation of $\beta_{\mathrm{M}}$. We used the distributions of the ozone obtained from ERA-Interim reanalysis data.

The backscattering coefficient of aerosols $\left(\beta_{\mathrm{M}}\right)$ was calculated by using the Fernald's equation to correct the attenuation (Fernald 1984) assuming an extinction $\left(\sigma_{\mathrm{M}}\right)$-to-backscatter $\left(\beta_{\mathrm{M}}\right)$ ratio of aerosols (so-called lidar ratio), $\sigma_{\mathrm{M}} / \beta_{\mathrm{M}}$, of fixed $30 \mathrm{sr}$. Kent and Hansen (1998) suggested a lidar ratio of 30 to $50 \mathrm{sr}$ (increasing with altitude). Kar et al. (2019) suggested a lidar ratio lower than $40 \mathrm{sr}$ for the polar stratosphere. Even if the actual lidar ratio is 50 $\mathrm{sr}$, the assumed fixed lidar ratio (30 sr) introduces an error in $\mathrm{R}$ smaller than 0.005 at stratospheric AOT lower than 0.004. This quantity of error should not influence the results calculated in this letter.

In the following sections, the results are presented using the backscattering ratio 

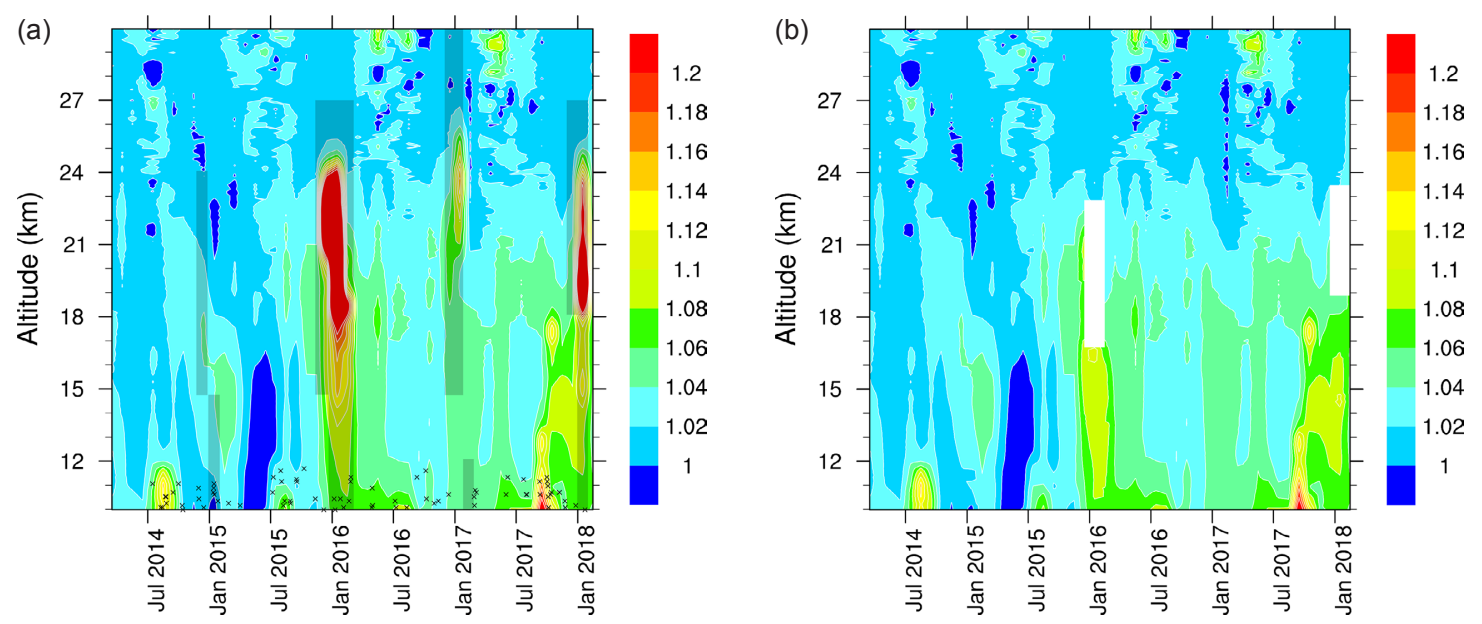

Fig. 1. (a) The crosses show the tropopause height on the days of the lidar observations. The crosses are plotted when the tropopause altitude is higher than $10 \mathrm{~km}$. The contour color plot shows the monthly averaged profiles of R. All the data points are included in the average. The shaded time-height areas include the data points where the temperature was lower than $T_{\mathrm{NAT}}$. These shaded areas may include PSC. Although low temperature $\left(<T_{\mathrm{NAT}}\right)$ was observed in December 2014, clear increase in R or VD was not identified. (b) The contour plot of the monthly averaged profiles of R after excluding the data points where the temperature is lower than $T_{\mathrm{NAT}}$.

$$
\mathrm{R}=\frac{\beta_{\mathrm{R}}+\beta_{\mathrm{M}}}{\beta_{\mathrm{M}}}
$$

and partly by the volume depolarization ratio

$$
\mathrm{VD}=\frac{\left(\beta_{\mathrm{R}}+\beta_{\mathrm{M}}\right)_{\mathrm{S}}}{\left(\beta_{\mathrm{R}}+\beta_{\mathrm{M}}\right)_{\mathrm{S}}+\left(\beta_{\mathrm{R}}+\beta_{\mathrm{M}}\right)_{\mathrm{P}}}
$$

where the subscripts R, M, S and P respectively indicate Rayleigh, Mie, perpendicular and parallel components of the backscattering coefficients (for details about VD see Shibata et al. 2018). R - 1 $=\beta_{\mathrm{M}} / \beta_{\mathrm{R}}$ is roughly proportional to the mixing ratio of aerosols. Since the stratospheric aerosols are mainly composed of liquid sulfate solution, the VD of the background aerosols is small (smaller than about 0.005). The aerosol particles are non-spherical if VD is larger than about 0.005 . The results are mainly presented with $\mathrm{R}$ in this letter, and VD is used only in limited cases since the signal to noise ratio of the perpendicular component in the stratosphere is not large enough in the season of the midnight sun.

Supplementary files provide the numerical data of Figs. 1 to 4. The values of the points out of range of the figures are given in these supplementary files.

\section{Results}

The crosses of Fig. 1a and sFig1 of supplemental files shows tropopause height according to the definition of the World Meteorological Organization and derived from temperature profiles observed by the balloon sounding at Ny Ålesund by the Alfred Wegener Institute at 12 UT on the days of the stratospheric aerosol observations. The average and standard deviation of the tropopause height on these days was 9.02 and $1.15 \mathrm{~km}$, respectively. The tropopause height showed lowest values in spring, and highest in summer. The height was frequently more than $10 \mathrm{~km}$, but never more than $12 \mathrm{~km}$ on the days of the observations throughout the four years.

The contour color plot of Fig. 1a shows the monthly averaged profiles of R. All the observed data points are included in the profiles of the monthly averaging. $\mathrm{R}$ during the three winters shows larger values. PSC was observed in the stratosphere when the temperature was a few degrees lower than the threshold temperature of nitric acid trihydrate (NAT), $T_{\mathrm{NAT}}$, approximated as below (Shibata et al. 1999; Shiraishi et al. 2003). We estimated $T_{\mathrm{NAT}}$ by assuming that the mixing ratio of nitric acid and water vapor are
10 ppbv and 5 ppmv, respectively. We approximated $T_{\mathrm{NAT}}$ as

$$
T_{\mathrm{NAT}}=-0.001 \times(z-10000)+205(\mathrm{~K}),
$$

where $z$ is the altitude in meter (see Fig. 2 of Shibata et al. 1999). The temperature in December and January was frequently lower than $T_{\mathrm{NAT}}$ or sometimes even lower than the frost point temperature, $T_{\text {ice }}\left(T_{\text {ice }} \lesssim T_{\mathrm{NAT}}-7(\mathrm{~K})\right.$, with the above mixing ratios), in the stratosphere over Ny Ålesund. Therefore, it is highly probable that the large values of $\mathrm{R}$ in December and January were caused by PSC when the temperature was lower than the threshold temperatures. Fig. 1b shows the contour plot of the monthly averaged profiles of $\mathrm{R}$ after excluding the data points where the temperature was lower than $T_{\mathrm{NAT}}$. The white area indicates no data point after exclusion. We can see how $\mathrm{R}$ changes with this exclusion by comparing Fig. 1a and Fig. 1b.

Figures $2 \mathrm{a}-2 \mathrm{~g}$ show the 3-km-width-height-range averaged $\mathrm{R}$ for all observed vertical profiles, and Fig. $2 \mathrm{~h}$ shows the AOT calculated by multiplying the integrated backscattering coefficient between 12 and $30 \mathrm{~km}$ in altitude by the assumed lidar ratio 30 sr. The crosses are the average of the data points including the situation where the temperature is lower than $T_{\mathrm{NAT}}$ and may also include the effect of PSC. The averages (and one standard deviation) for the dots of $\mathrm{R}$ at each height range and of AOT are (a) 1.044 (0.037), (b) 1.040(0.033), (c) 1.039(0.029), (d) 1.032(0.025), (e) $1.020(0.020)$, (f) $1.013(0.017),(\mathrm{g}) 1.014(0.022)$, and (h) 0.0022 (0.0016), respectively.

\section{Discussion}

The eruption of Kelud $\left(8^{\circ} \mathrm{S}, 112^{\circ} \mathrm{E}\right)$ in February 2014 injected aerosols into the stratosphere (Kristiansen et al. 2015). The plume from the Kelud eruption was observed between 17 and $24 \mathrm{~km}$ in altitude at the Observatory Haute-Provence (OHP, $\left.44^{\circ} \mathrm{N}, 6^{\circ} \mathrm{E}\right)$, France from Decemver 2014 to April 2015 (Khaykin et al. 2017), but was not clear at Tsukuba $\left(36^{\circ} \mathrm{N}, 140^{\circ} \mathrm{E}\right)$, Japan (Sakai et al. 2016). These observations at two sites probably indicate that the plume was not globally uniform even one year after the eruption. We could not detect any volcanic aerosols over Ny Ålesund as there was no apparent increase in R in 2015 in Fig. 1a or even in individual profiles (not shown).

It has been reported that the wildfire in northwest Canada in August 2017 injected smoke into the stratosphere. The smoke was observed over Europe from August 2017 to January 2018 (Baars et al. 2019). Khaykin et al. (2018) reported a smoke event causing increase in $\mathrm{R}$ up to 10 between 18 and $20 \mathrm{~km}$ in altitude observed 


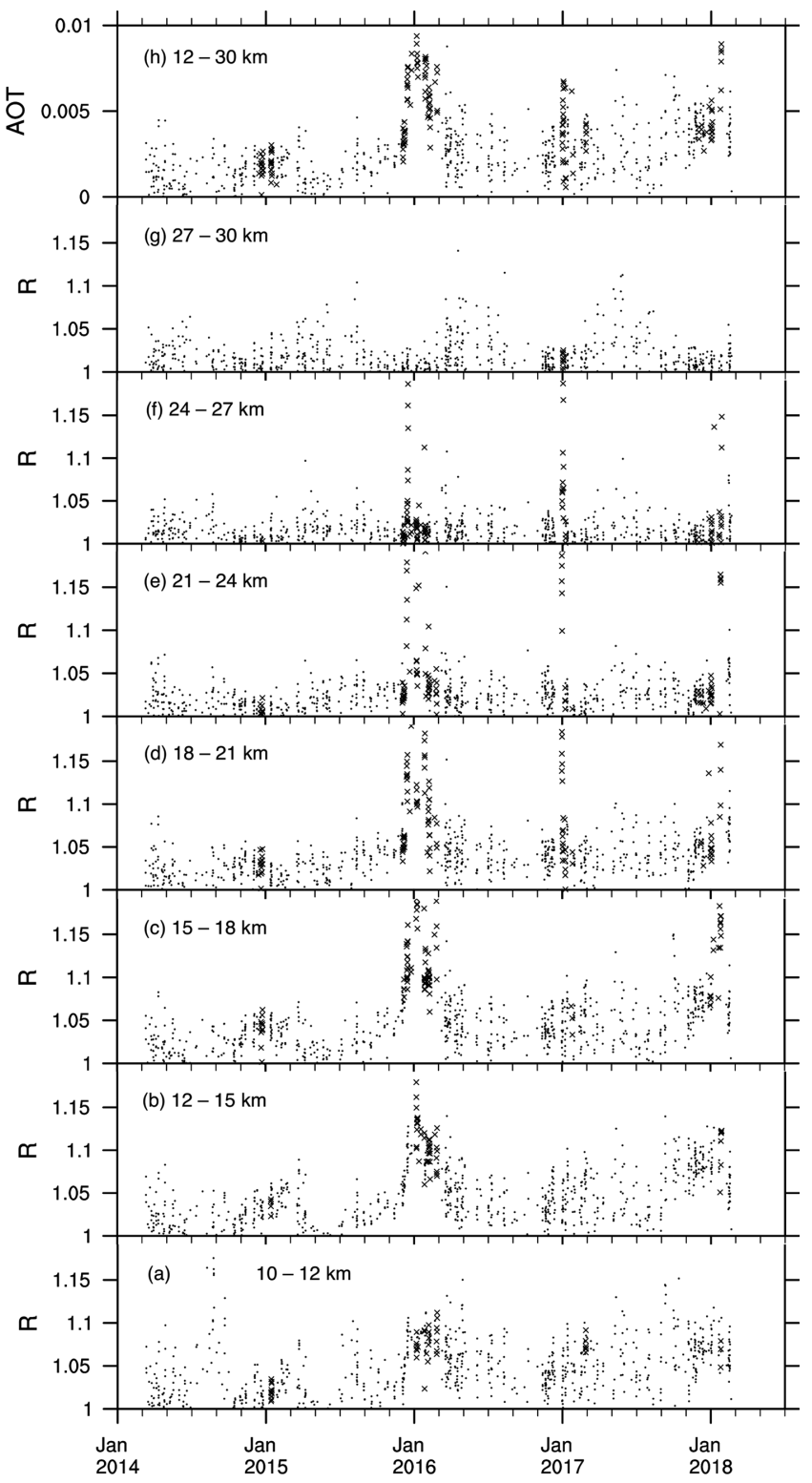

Fig. 2. (a)-(g) The R averaged between the height interval for each profile. (h) AOT with the height interval between 12 and $30 \mathrm{~km}$. The crosses are the average of the data points including where the temperature is lower than $T_{\mathrm{NAT}}$.

at OHP in August 2017. In our observations, it is difficult to ascertain whether there is an apparent increase of $\mathrm{R}$ in 2017 in the averaged profiles presented in Fig. 1a. However, as shown in the individual profiles of Fig. 3, we can see increases of $\mathrm{R}$ and VD from September 2017 to January 2018. Usually the values of VD in undisturbed stratosphere are less than 0.005 . As we can see in Fig. 3, the profiles of VD show values larger than 0.005 from September 2017. Increased values of $\mathrm{R}$ were observed on 12 September 2017 and later at altitudes where VD increased. Narrower, $\sim 1 \mathrm{~km}$, vertical layers of $\mathrm{R}$ and VD were observed until the end of October 2017. Wider, $>\sim 5 \mathrm{~km}$, layers of up to $20 \mathrm{~km}$ in altitude was observed in November and December 2017. The observed characteristics of the smoke approximately agree with that observed over Europe (Baars et al. 2019).

Figure 4 shows the contour plots of monthly variations in $\mathrm{R}$ by averaging for each month through the three years from March 2014 to February 2017 before the effects of the forest fire and after excluding the data points where the temperature was lower than

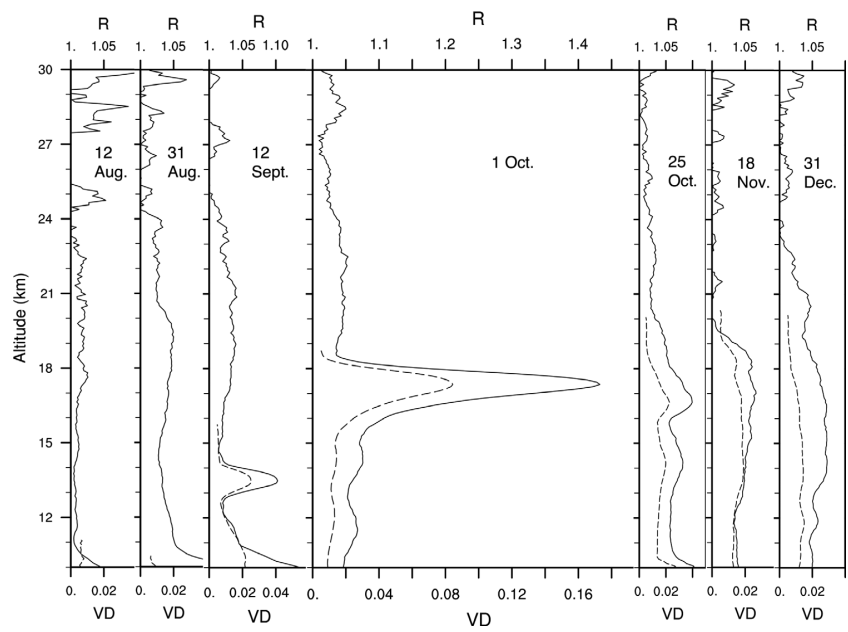

Fig. 3. Selected profiles of R (solid) and VD (broken) from August to December 2017. The profiles of VD are plotted for the heights where VD is larger than 0.005 .

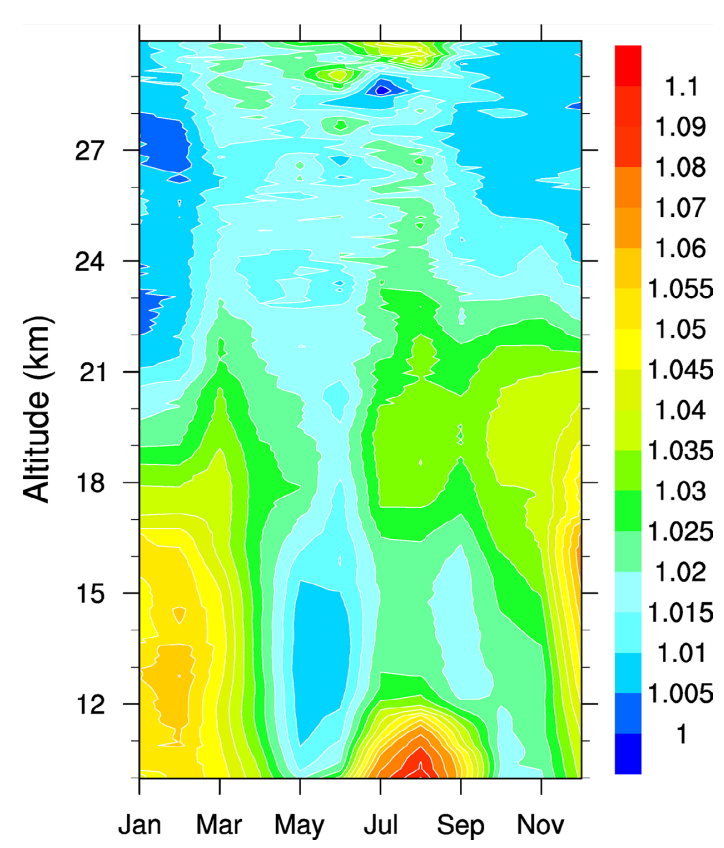

Fig. 4. The color plot of the monthly averaged $\mathrm{R}$ for three years excluding the data points where the temperature is lower than $T_{\mathrm{NAT}}$.

$T_{\mathrm{NAT}}$. The largest $\mathrm{R}$ values lower than $12 \mathrm{~km}$ in altitude in summer is consistent with the summer maximum of the tropospheric aerosols (Shibata et al. 2018) when the tropopause height is usually more than $10 \mathrm{~km}$ (Fig. 1a and sFig1). The vertical profile of $\mathrm{R}$ takes a maximum value of about 1.05-1.06 at altitudes between 13 and $16 \mathrm{~km}$ from December to March, and about 1.02-1.04 at altitudes between 17 and $20 \mathrm{~km}$ from April to November. These changes in the altitudes of the stratospheric R-maximum (Rmax) and the values of the Rmax are summarized by bold solid lines in Figs. 5a and 5b, respectively. The thin solid lines of Fig. 5a show the altitudes where $\mathrm{R}$ is $(\mathrm{R} \max -1) / 2$, or the half mixing ratio of Rmax. We can find the altitudes of the half mixing ratio at the top side of the stratospheric aerosol layer for all months. However, we can find the altitudes only for a few months at the bottom side of the layer.

As was described in the introduction, there is only one report 

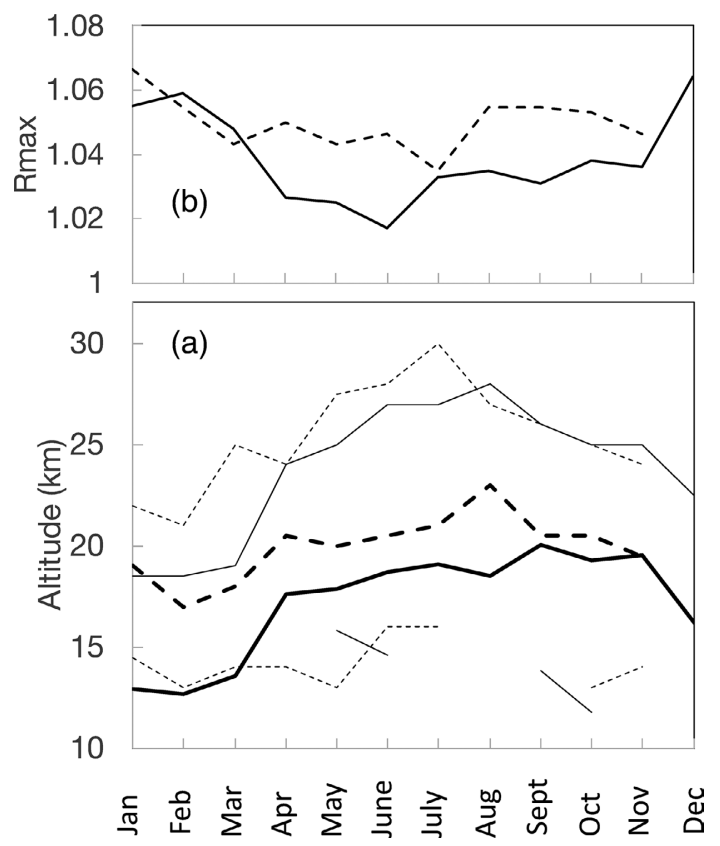

Fig. 5. (a) The altitudes of Rmax (bold solid) and (Rmax - 1)/2 (thin solid) at Ny Ålesund. The altitudes of Rmax (bold broken) and (Rmax - 1)/2 (thin broken) at northern Norway. (b) The Rmax at Ny Ålesund (bold solid) and northern Norway (bold broken).

of year-round lidar observations presenting seasonal variation of stratospheric aerosols from 2014 to 2017 over the low Arctic over northern Norway (Langenback et al. 2019). The observations at northern Norway show the maximum and minimum $\mathrm{R}$ occurring at about $19 \mathrm{~km}$ in altitude in January and at about $21 \mathrm{~km}$ in altitude in July, respectively. $\mathrm{R}$ at the wavelength of $1064 \mathrm{~nm}$ is 1.4 in January at $19 \mathrm{~km}$ in altitude and 1.2 in July at $21 \mathrm{~km}$ in altitude. These values were obtained from Fig. 10 of the paper by Langenback et al. $\mathrm{R}$ at $1064 \mathrm{~nm}\left(\mathrm{R}_{1064}\right)$ can be converted into $\mathrm{R}$ at $532 \mathrm{~nm}$ $\left(\mathrm{R}_{532}\right)$ by

$$
\mathrm{R}_{532}=1+\left(\mathrm{R}_{1064}-1\right) / 6.02
$$

(eq. (5) of Khaykin et al. 2017) with wavelength exponent of the backscattering coefficient of aerosols at the wavelengths 532 and $1064 \mathrm{~nm}$ set at -1.5 (Jäger and Deshler 2002). The above maximum and minimum values of $\mathrm{R}_{1064}, 1.4$ and 1.2 , are converted respectively into the values of $\mathrm{R}_{532}, 1.07$ and 1.03 . These changes in the altitudes and in the values of the Rmax at northern Norway are also summarized by bold broken lines in Figs. $5 \mathrm{a}$ and $5 \mathrm{~b}$, respectively. The thin broken lines of Fig. 5a show the altitudes where $\mathrm{R}$ is $(\operatorname{Rmax}-1) / 2$.

The stratospheric aerosol layer observed at both sites shows roughly similar seasonal variations in the altitude and value of Rmax. The altitude of Rmax is lower from January to March and higher from June to October at both sites. The altitudes at Ny Ålesund are about $5 \mathrm{~km}$ and a few km lower than at northern Norway in winter and in spring and summer respectively. The altitudes at both sites agree in fall. Rmax at both sites are roughly in agreement in winter. The Rmax at Ny Ålesund is about 0.02 smaller in other seasons.

Stratospheric aerosols are treated as possible conservative tracers if they are not affected by extreme temperature fluctuations as for the case of PSC (e.g. McCormick and Wang 1987). The observed winter maximum of aerosols over both sites is consistent with the stratospheric active dynamical extratropical pumping in winter (Holton et al. 1995), and with the higher aerosol mixing ratios because the higher-mixing-ratio-aerosols at lower latitudes (Hitchman et al. 1994) are transported to higher latitudes in winter. In addition, the stratospheric dynamical subsidence of the polar vortex is effective in the high Arctic. Therefore, the dynamical transport process could cause the difference in the vertical profiles of $\mathrm{R}$ between the high and low Arctic. Numerical simulations in the future using a chemical transport model will help clarify the relationship between the dynamics and the vertical profiles.

Shibata et al. (2018) normalized tropospheric lidar data by assuming $\mathrm{R}$ averaged between 12 and $15 \mathrm{~km}$ to be 1.10 by a preliminary estimation of $\mathrm{R}$. The averaged $\mathrm{R}$ between 12 and $15 \mathrm{~km}$ is 1.040 by the more careful estimation used in this study. Their assumed value of 1.10 introduced about $6 \%$ overestimates in the tropospheric $\mathrm{R}$, and about $10 \%$ overestimates in $\beta_{\mathrm{M}}$ in the lower troposphere. If we use the value of 1.040 for the normalization of tropospheric observations in the high Arctic from 2014 to 2017, it results in a 3\% relative error in $\mathrm{R}$.

\section{Conclusion}

We have presented for the first time observations of the lidar observed stratospheric aerosols over the high Arctic on almost all clear days for four years. The stratosphere over the high Arctic was apparently free from volcanic aerosols and forest fire smoke from March 2014 to July 2017. The only significant aerosol perturbation was caused by PSC in the winters. We removed the effect of PSC by the threshold temperature of their formation. The observed Rmax of stratospheric aerosols after removal of PSC showed seasonal variation with maximum values of about $1.05-$ 1.06 in winter to spring and minimum values of about $1.02-1.04$ in spring to fall. The altitude of Rmax is lowest between 13 and $16 \mathrm{~km}$ in winter and highest between 17 and $20 \mathrm{~km}$ in spring to fall. The altitude of Rmax shows approximately similar seasonal variation to the variation observed at the low Arctic, northern Norway. However, the altitude of Rmax at Ny Ålesund is several $\mathrm{km}$ lower than the altitude at the low Arctic in the seasons from winter to summer, and lowest at about $5 \mathrm{~km}$ in winter. The Rmax observed at the high Arctic agrees well with the wavelength converted Rmax at the low Arctic in winter, but is a few percent smaller in other seasons.

\section{Acknowledgements}

We thank the Arctic Environment Research Center of the National Institute of Polar Research for providing us with the facilities to conduct our research at Ny-Ålesund. We thank the Alfred Wegener Institute for providing us with the balloon sounding data. We thank the European Centre for Medium-Range Weather Forecasts for making available the ERA-Interim reanalysis data. This study was supported by the Japan Society for the Promotion of Science KAKENHI grants (25340020, 25257201 and 16H02702).

Edited by: D. Zhang

\section{Supplementary files}

sFig1.pdf: The tropopause height as defined by WMO on the days of observations.

Fig1.csv: The numerical data of Fig. 1.

Fig2.csv: The numerical data of Fig. 2.

Fig3.csv: The numerical data of Fig. 3.

Fig4.csv: The numerical data of Fig. 4.

\section{References}

Baars H., A. Ansmann, K. Ohneiser, M. Haarig, R. Engelmann, D. Althausen, I. Hanssen, M. Gausa, A. Pietruczuk, A. Szkop, I. S. Stachlewska, D. Wang, J. Reichardt, A. Skupin, I. Mattis, T. Trickl, H. Vogelmann, F. Navas-Guzmán, A. Haefele, K. Acheson, A. A. Ruth, B. Tatarov, D. Müller, Q. Hu, T. Podvin, P. Goloub, I. Veselovskii, C. Pietras, M. Haeffelin, 
P. Fréville, M. Sicard, A. Comerón, A. J. F. García, F. M. Menéndez, C. Córdoba-Jabonero, J. L. Guerrero-Rascado, L. Alados-Arboledas, D. Bortoli, M. J. Costa, D. Dionisi, G. L. Liberti, X. Wang, A. Sannino, N. Papagiannopoulos, A. Boselli, L. Mona, G. D'Amico, S. Romano, M. R. Perrone, L. Belegante, D. Nicolae, I. Grigorov, A. Gialitaki, V. Amiridis, O. Soupiona, A. Papayannis, R.-E. Mamouri, A. Nisantzi, B. Heese, J. Hofer, Y. Y. Schechner, U. Wandinger, and G. Pappalardo, 2019: The unprecedented 2017-2018 stratospheric smoke event: Decay phase and aerosol properties observed with the EARLINET. Atmos. Chem. Phys., 19, 15183-15198, doi:10.5194/acp-19-15183-2019.

Fernald, F. G., 1984: Analysis of atmospheric lidar observations: Some comments. Appl. Opt., 23, 652-653, doi:10.1364/AO. 23.000652.

Hitchman, M. H., M. McKay, and C. R. Trepte, 1994: A climatology of stratospheric aerosol. J. Geophys. Res. Atmos., 99, 20689-20700, doi:10.1029/94JD01525.

Holton, J. R., P. H. Haynes, M. E. McIntyre, A. R. Douglass, R. B. Rood, and L. Pfister, 1995: Stratosphere-troposphere exchange. Rev. Geophys., 33, 403-439, doi:10.1029/95RG 02097.

Jäger, H., and T. Deshler, 2002: Lidar backscatter to extinction, mass and area conversions for stratospheric aerosols based on mid- latitude balloon-borne size distribution measurements. Geophys. Res. Lett., 29, 1929, doi:10.1029/2002GL 015609.

Kar, J., K.-P. Lee, M. A. Vaughan, J. L. Tackett, C. R. Trepte, D. M. Winker, P. L. Lucker, and B. J. Getzewich, 2019: CALIPSO level 3 stratospheric aerosol profile product: Version 1.00 algorithm description and initial assessment. Atmos. Meas. Tech., 12, 6173-6191, doi:10.5194/amt-12-6173-2019.

Kent, G. S., and G. M. Hansen, 1998: Multiwavelength lidar observations of the decay phase of the stratospheric aerosol layer produced by the eruption of Mount Pinatubo in June 1991. Appl. Opt., 37, 3861-3872, doi:10.1364/AO.37. 003861.

Khaykin, S. M., S. Godin-Beekmann, P. Keckhut, A. Hauchecorne, J. Jumelet, J.-P. Vernier, A. Bourassa, D. A. Degenstein, L. A. Rieger, C. Bingen, F. Vanhellemont, C. Robert, M. DeLand, and P. K. Bhartia, 2017: Variability and evolution of the midlatitude stratospheric aerosol budget from 22 years of ground-based lidar and satellite observations. Atmos. Chem. Phys., 17, 1829-1845, doi:10.5194/acp-17-1829-2017.

Khaykin, S. M., S. Godin-Beekmann, A. Hauchecorne, J. Pelon, F. Ravetta, and P. Keckhut, 2018: Stratospheric smoke with unprecedentedly high backscatter observed by lidars above southern France. Geophys. Res. Lett., 45, 1639-1646, doi:10.1002/2017GL076763.

Kristiansen, N. I., A. J. Prata, A. Stohl, and S. A. Carn, 2015: Stratospheric volcanic ash emissions fromthe 13 February 2014 Kelut eruption. Geophys. Res. Lett., 42, 588-596, doi: 10.1002/2014GL062307.

Langenbach, A., G. Baumgarten, J. Fiedler, F.-J. Lübken, C. von Savigny, and J. Zalach, 2019: Year- round stratospheric aerosol backscatter ratios calculated from lidar measurements above northern Norway. Atmos. Meas. Tech., 12, 4065-4076, doi:10.5194/amt-12-4065-2019.

Lowe, D. A., and R. MacKenzie, 2008: Polar stratospheric cloud microphysics and chemistry. J. Atmos. Solar-Terres. Phys., 70, 13-40, doi:10.1016/j.jastp.2007.09.011.

McCormick, M. P., and P.-H. Wang, 1987: Satellite measurements of stratospheric aerosols. Transport Processes in the Middle Atmosphere (Nato Science Series C:) 1987th Edition, G. Visconti, and R. Garcia, Eds., Springer, 103-120, 485 pp.

Sakai, T., O. Uchino, T. Nagai, B. Liley, I. Morino, and T. Fujimoto, 2016: Longterm variation of stratospheric aerosols observed with lidars over Tsukuba Japan, from 1982 and Lauder, New Zealand, from 1992 to 2015. J. Geophys. Res. Atmos., 121, 10283-10293, doi:10.1002/2016JD025132.

Shibata, T., K. Shiraishi, H. Adachi, Y. Iwasaka, and M. Fujiwara, 1999: On the lidar-observed sandwich structure of polar stratospheric clouds (PSCs): 1. Implications for the mixing state of the PSC particles. J. Geophys. Res: Atmos., 104, 21603-21611, doi:10.1029/1999JD900333.

Shibata, T., K. Shiraishi, M. Shiobara, S. Iwasaki, and T. Takano, 2018: Seasonal variations in high Arctic free tropospheric aerosols over Ny-Ålesund, Svalbard, observed by groundbased lidar. J. Geophys. Res. Atmos., 123, doi:10.1029/2018 JD028973.

Shiraishi, K., M. Fujiwara, T. Shibata, and Y. Iwasaka, 2003: Lidar observations of polar stratospheric clouds over Ny-Aalesund in the winters of 1994/95-1996/97: Impact of the temperature and the temperature history on the PSC structure. $J$. Meteor. Soc. Japan, 81, 1457-1470, doi:10.2151/jmsj.81. 1457.

Shiraishi, K., 2010: Physical chemistry of polar stratospheric cloud and global environmental change. Earozoru Kenkyu, 25, 219-225, doi:10.11203/jar.25.219.

Manuscript received 27 October 2020, accepted 11 December 2020 SOLA: https://www.jstage.jst.go.jp/browse/solal 